\title{
Conhecimento dos graduandos de enfermagem sobre equipamentos de proteção individual: a contribuição das instituições formadoras ${ }^{1}$
}

\section{Nursing graduating student's know ledge on personal protective equipment: contributions of educational institutions}

\section{Conocimiento de los graduandos de enfermería sobre equipos de seguridad: la aportación de las instituciones formadoras}

\author{
Adenícia Custódia Silva e Souza', Heliny Carneiro Cunha Neves", Anaclara Ferreira Veiga Tipple" \\ Silvana de Lima Vieira dos Santos ${ }^{\mathrm{IV}}$, Cecília Ferreira da Silvav, \\ Regiane Aparecida dos Santos Barreto ${ }^{\mathrm{Vl}}$
}

\begin{abstract}
RESUMO
Estudo objetivou verificar a compreensão dos alunos acerca do uso de Equipamento de proteção individual (EPI) na perspectiva do controle de infecção e identificar a contribuição dos cursos de graduação em enfermagem para a construção do conhecimento dos graduandos sobre esta temática. Realizado com 182 $(58,3 \%)$ graduandos concluintes dos cursos de enfermagem em Instituições de Ensino Superior do Estado de Goiás no ano de 2005. Os dados foram obtidos por meio de um questionário após aprovação no Comitê de Ética em Pesquisa e analisados por meio de estatística descritiva. Os resultados mostram múltiplas condutas dos alunos no uso e manuseio de jaleco, luvas, máscara, óculos e gorro. Embora relatem fazer uso de EPI, não conhecem suas finalidades de uso, ainda que tenham sido abordadas em disciplina curricular. $O$ conhecimento é inconsistente e sinaliza falha no processo de ensino. Verificamos uma vulnerabilidade dos acadêmicos em relação à prevenção de infecções adquiridas ocupacionalmente.
\end{abstract}

Palavras chave: Equipamentos de proteção; Precauções universais; Educação em Enfermagem.

\section{ABSTRACT}

This study aimed at verifying students' understanding on the use of personal protective equipment (PPE) under the perspective of infection control and identifying nursing graduation courses contribution to the construction of graduating students' knowledge on this issue. It was carried out with 182 (58.3\%) nursing graduating students in Higher Education Institutions in the State of Goiás in the year of 2005. Data was collected through a questionnaire after approval of the Research Ethics Committee and assessed through descriptive statistics. The outcomes showed students multiple behavior on the use and handling of coats, gloves, masks, goggles, and caps. Despite their reports of using PPE, they do not know why to use them, even though they have studied about them in the curriculum. Knowledge is inconsistent and signals to failure in the teaching process. We verified a student's vulnerability regarding prevention of workrelated infections.

Key words: Protective devices; Universal precautions; Nursing Education

\section{RESUMEN}

El estudio tuvo como objetivo verificar la comprensión de los alumnos a cerca del uso de equipos de seguridad en la perspectiva del control de infección e identificar la aportación de los cursos de graduación en enfermería para la construcción del conocimiento de los graduandos sobre esta temática. Realizado con $182(58,3 \%)$ graduandos concluyentes de los cursos de enfermería en Instituciones de

\footnotetext{
Trabalho apresentado e discutido no III CONPEEX (Congresso de Pesquisa, Ensino e Extensão) e no VI Congresso Pan-Americano e $X$ Congresso Brasileiro de Controle de Infecção e Epidemiologia Hospitalar.

' Enfermeira. Professora Doutora Adjunto III da Faculdade de Enfermagem da UFG (FEN/UFG), coordenadora do Núcleo de Estudos e Pesquisa em Infecção Hospitalar (NEPIH) da FEN/UFG. Goiânia/GO. E-mail: adenicia@fen.ufg.br

"Enfermeira, mestranda do programa de pós-graduação em enfermagem da FEN/UFG. Goiânia/GO. E-mail: nynne_cunha@yahoo.com.br

III Enfermeira, Professora Adjunto III da Faculdade de Enfermagem da UFG, vice-coordenadora do NEPIH. Goiânia/GO. E-mail: anaclara@fen.ufg.br

IV Enfermeira, Mestre. Professora da Universidade Salgado de Oliveira. Membro efetivo do NEPIH. Goiânia/GO. E-mail: silvanalvs@hotmail.com

${ }^{V}$ Enfermeira, Ex-bolsista de iniciação científica do NEPIH pelo CNPq. E-mail: cissa_ferreira_silva@hotmail.com

vi Enfermeira, Mestre, Professora da Faculdade de Enfermagem da UFG. Goiânia/GO. E-mail: remajuau@yahoo.com.br
} 
Enseñanza Superior del Estado de Goiás en el año de 2005. Los datos fueron obtenidos por medio de un cuestionario después de aprobación en el Comité de Ética en Investigación y analizados por medio de estadística descriptiva. Los resultados muestran múltiplas conductas de los alumnos en el uso y manoseo de chaleco, guantes, máscaras, gafas y gorro. Aun relaten hacer uso de equipos de seguridad, no conocen sus finalidades de uso,

\section{NTRODUÇÃO}

Ao realizar atendimento hospitalar, os enfermeiros estão constantemente expostos a vários riscos durante a execução de suas atividades, principalmente por manusear diretamente o sangue e fluidos corporais de pacientes, potenciais portadores de doenças os quais são possíveis fontes de transmissão de patógenos.

Sendo assim, a exposição ocupacional por material biológico é entendida como a possibilidade de contato com sangue e fluidos orgânicos no ambiente de trabalho, e as formas de exposição incluem inoculação percutânea, por intermédio de agulhas ou objetos cortantes, e o contato direto com pele e ou mucosas ${ }^{(1)}$.

A exposição ocupacional a material biológico é uma das questões mais proeminentes na área de segurança ocupacional, pois coloca o profissional de saúde em risco de adquirir infecções transmitidas por via sanguínea. Dentre essas infecções, as mais preocupantes são a aids, a hepatite $\mathrm{B}$ e a hepatite $C^{(2)}$.

$\mathrm{Na}$ década de 80 com a emergência dos microrganismos multidrogaresistentes e novos patógenos, e a situação de epidemia e endemia relacionadas a infecção nosocomial levaram a indagações que culminaram com a revisão do "Guideline for Isolation Precautions in Hospital", publicado em 1983, cuja estratégia encorajava a tomada de decisão por parte do profissional, definindo a necessidade do uso de EPI, conforme exposição a materiais contaminados $^{(3)}$.

Em 1987, na tentativa de diminuir o risco de transmissão ocupacional de patógenos do sangue e infecções, os CDC (Center for Disease Control and Prevention) publicaram as aun que tengan sido abordadas en asignatura curricular. El conocimiento es inconsciente y señaliza falla en el proceso de enseñanza. Verificamos una vulnerabilidad de los académicos con relación a la prevención de infecciones adquiridas en el oficio.

Palabras clave: Equipos de seguridad; Precauciones universales; Educación en Enfermería.

Precauções Universais (PU), que indicam o uso de barreiras para a proteção do profissional como o avental, luvas, óculos, com grande ênfase para a lavagem de mãos e cuidado com material perfurocortante ${ }^{(3)}$.

Em 1996, foi reformulada e denominada de Precauções Padrão (PP) sintetizando a maioria das PU e das precauções com substâncias corpóreas, em um conjunto de precauções a serem adotadas para o atendimento a todos os clientes, independente do conhecimento do seu estado infeccioso. Tal norma amplia as precauções para todos os fluídos corpóreos e inclui apropriada lavagem das mãos e precauções do tipo barreira, com o uso de luvas para o manuseio de todos os fluidos orgânicos, dentre outros ${ }^{(3)}$.

Em face do conhecimento dos riscos ocupacionais, a prevenção da exposição a material biológico tornou-se medida prioritária, o uso das Precauções Padrão (PP) constitui-se, portanto em prevenção primária da exposição ocupacional, sendo considerada uma maneira segura e necessária para reduzir a exposição ocupacional a sangue e outros fluidos orgânicos ${ }^{(2)}$.

As PP incluem o uso de Equipamento de Proteção Individual visando à proteção do profissional da saúde. O equipamento de proteção Individual refere-se ao uso de barreiras utilizadas para proteger pele, mucosas e roupas do profissional, do contato com agentes infecciosos, selecionados de acordo com o critério do profissional a partir da natureza do procedimento e possibilidade do modo de transmissão dos patógenos ${ }^{(4)}$.

Assim, prevenir infecção depende da proteção por meio de barreiras entre o hospedeiro e os microrganismos. As barreiras 
Souza ACS, Neves HCC, Tipple AFV, Santos SLV, Silva CF, Barreto RAS. Conhecimento dos graduandos de enfermagem sobre equipamentos de proteção individual: a contribuição das instituições formadoras. Revista Eletrônica de Enfermagem [Internet]. 2008; 10(2):428-437. Available from: http://www.fen.ufg.br/revista/v10/n2/v10n2a14.htm

protetoras podem ser físicas, mecânicas ou químicas, e previnem a disseminação de microrganismos infecciosos de um cliente para outro, ou do profissional para o cliente e viceversa. As medidas de prevenção incluem desde a lavagem das mãos e uso do Equipamento de Proteção Individual (EPI), até os processos de limpeza, desinfecção e esterilização ${ }^{(5)}$.

O uso de Equipamento de Proteção Individual é fundamental para uma prática segura em serviços de assistência à saúde. Entretanto, esta segurança se efetivará não apenas pela adoção destes equipamentos, mas pela forma como são utilizados, incluindo os processos de descontaminação, rotinas de troca, dentre outros ${ }^{(5)}$.

Contudo, não somente a eficácia das medidas de precaução deve ser periodicamente avaliada e aprimorada, mas sobretudo a adesão dos profissionais de saúde a estas medidas. O uso adequado do EPI inclusive o mau uso também deve ser avaliado.

Observou-se que o equipamento de proteção era utilizado pelas enfermeiras de maneira diferenciada sendo seu uso baseado no nível de risco durante o trabalho e de acordo com a interação com o paciente ${ }^{(6)}$.

Percebeu-se então que a adesão ao uso do EPI está intimamente relacionada à percepção que os profissionais têm acerca dos riscos a que estão expostos e da susceptibilidade a estes $\operatorname{riscos}^{(7)}$.

Durante o curso de graduação em Enfermagem, os estudantes devem adquirir conhecimento sobre o uso do Equipamento de Proteção Individual. É durante a prática que os alunos se deparam com situações que exigem a utilização destes equipamentos de segurança.

Nem sempre a importância da utilização do EPI tem sido construída de forma eficaz durante a graduação. Tem-se observado na prática, que enfermeiras (os) recém-graduadas (os) não têm sido capazes de transformar a sua realidade cotidiana referente a adoção dessa importante medida de prevenção e controle de infecção nos Serviços de Assistência à Saúde.

Destaca-se que o ensino de graduação em enfermagem, assim como de outros cursos na área da saúde, até recentemente, imprimiam um ensino hospitalocêntrico, com foco na doença, na unicausalidade e verticalizado, tendo o professor como o centro do processo ensinoaprendizagem $^{(8)}$. Essas características de ensino que perduraram por várias décadas produziram a dicotomia entre teoria e prática e contribuíram para a formação de profissionais descontextualizados da realidade de saúde do país e com pouca competência para transformar essa realidade.

As Diretrizes Curriculares Nacionais do Curso de Graduação em Enfermagem instituídas em 2001 ${ }^{(9)}$ permitiram aos cursos de enfermagem reformularem seus currículos direcionando-os para um processo de ensinoaprendizagem que contemple novos paradigmas tanto no ensino quanto na assistência. Contudo, a implementação desse novo currículo é recente nos cursos de graduação em enfermagem no Estado de Goiás e, ainda não se tem egressos desse currículo no mercado de trabalho.

Considerando o exposto, este estudo teve como objetivos: Verificar a compreensão dos alunos de graduação em enfermagem acerca do uso de equipamento de proteção individual na perspectiva do controle de infecção, e Identificar a contribuição dos cursos de graduação em enfermagem para a construção do conhecimento dos graduandos sobre o uso do EPI.

\section{MÉTODOS}

Estudo descritivo de abordagem quantitativa, realizado com alunos do último ano/semestre dos cursos de enfermagem de Instituições de Ensino Superior de Enfermagem do Estado de Goiás, no período de abril a junho de 2005.

Identificou-se dez cursos de graduação em enfermagem credenciados/autorizados pelo Ministério da Educação e Cultura (MEC) e em funcionamento no Estado de Goiás, destes, apenas cinco foram elegíveis, por terem alunos cursando o último ano.

Para obtenção de amostra representativa realizou-se um teste piloto com os alunos do penúltimo ano, a partir do qual foi realizado cálculo com auxílio do Statistical, recurso estatístico do software Epi-info versão 3.3 de 2004, obtendo uma amostra de 168 indivíduos 
que representam $54 \%$ do total da população, com índice de confiabilidade de 95\%.

Observou-se os aspectos ético-legais de pesquisa em seres humanos, com aprovação do projeto pela Comissão de Ética em Pesquisa da Santa Casa de Misericórdia de Goiânia, protocolo 010/2003. Após autorização do Diretor de cada Faculdade, foi realizada a coleta de dados, na qual os alunos foram abordados em sala de aula e orientados sobre o estudo e os que concordaram assinaram o termo de consentimento livre e esclarecido.

Os dados foram obtidos por meio de questionário construído de acordo com o preconizado pelas PP para o uso e manuseio do $\mathrm{EPI}^{(3)}$, avaliado por três profissionais com conhecimento em Controle de Infecção.

Os dados foram processados no programa Epi-info versão 3.3 de 2004, apresentados em figuras e tabelas e analisados por meio da estatística descritiva.

\section{RESULTADOS E DI SCUSSÃO}

Dos cinco cursos de enfermagem que fizeram parte do estudo $182(58,3 \%)$ alunos participaram da amostra, sendo 145 (79,6\%) do sexo feminino, $21 \quad(11,5 \%)$ do sexo masculino. Em relação à faixa etária, houve um predomínio de adultos jovens entre 20 a 30 anos de idade.

A graduação representa a oportunidade de acesso às informações atualizadas, acerca do uso e manuseio do EPI, para a construção do conhecimento e desenvolvimento de hábitos e habilidades dos profissionais, para atuação de forma segura nessa área. A prática profissional é o reflexo do processo ensino-aprendizagem, sendo o período da graduação fundamental para o desenvolvimento dessas competências.

Ao serem questionados quanto à existência das disciplinas curriculares, no momento da formação acadêmica 168 (92,3\%) reconheceram que houve abordagem do tema equipamento de proteção individual (EPI) e todos afirmaram fazer uso do EPI durante as atividades práticas.

O fato de ter disciplinas que abordam a indicação e uso do EPI, não significa que este tema está sendo trabalhado de forma a promover a construção do conhecimento e mudança de hábitos dos alunos. Um dos fatores dificultadores para o processo ensinoaprendizagem é a grade curricular das Instituições de Ensino Superior, composta por disciplinas quase sempre sem conexão entre elas, e que não oferecem ao aluno a possibilidade de juntar os fragmentos desse conhecimento de forma clara e consciente para a sua práxis no cotidiano do trabalho. A abordagem do EPI deve ser realizada de forma contínua, integrando teoria e prática, para que os alunos possam adquirir uma postura ética, reflexiva e segura acerca da segurança ocupacional.

Vários fatos indicam a real necessidade de um investimento anterior à prática profissional, que tem se mostrado insuficiente quanto ao ensino e à prática do controle de infecção. Investe-se incansavelmente no graduando, para que, durante a formação, adquira competência para executar um procedimento esperado em seu exercício profissional, mas a ênfase à prática do controle de infecção fica a desejar ${ }^{(10)}$.

A utilização do equipamento de proteção individual representa uma barreira de proteção que pode diminuir os contatos com sangue, fluídos corporais e outras excretas, sendo que em algumas circunstâncias, reduz significantemente a exposição aos riscos existentes no ambiente de trabalho(11).

Em relação ao que é considerado EPI pelos graduandos, observou-se que outros itens foram incluídos: avental, capote, botas, sapato fechado, propé, máscara $\mathrm{N}-95$ e unissex. Isso deixa claro que os acadêmicos de enfermagem além de usá-los, conhecem estes EPI.

A NR 32/2005 do Ministério do Trabalho e emprego inclui o calçado fechado como EPI obrigatório para os profissionais da área de saúde com a finalidade de eliminar risco de exposição à material biológico(12).

Verificou-se que $170(93,4 \%)$ dos alunos afirmaram fazer uso do jaleco em todas as atividades práticas, Tabela 1 . 
Tabela 1: Distribuição do EPI segundo a rotina de utilização pelos acadêmicos de Enfermagem. Goiás, 2005. ( $n=182)$.

\begin{tabular}{ccccccccccc}
\hline \multirow{2}{*}{ EPI } & \multicolumn{2}{c}{ Sempre } & \multicolumn{2}{c}{ Situações Específicas } & \multicolumn{2}{c}{ Raramente } & \multicolumn{2}{c}{ Nunca } & \multicolumn{2}{c}{ Não responderam } \\
& $\mathbf{N}$ & $\%$ & $\mathbf{N}$ & $\%$ & $\mathbf{N}$ & $\%$ & $\mathbf{N}$ & $\%$ & $\mathbf{N}$ & $\%$ \\
\hline Jaleco & 170 & 93,4 & 9 & 5 & 0 & 0 & 0 & 0 & 3 & 1,6 \\
Luvas & 96 & 52,7 & 85 & 46,7 & 0 & 0 & 0 & 0 & 1 & 0,5 \\
Máscara & 52 & 28,5 & 119 & 65,3 & 4 & 2,1 & 0 & 0 & 7 & 3,8 \\
Óculos & 21 & 11,5 & 110 & 60,4 & 26 & 14,2 & 14 & 7,6 & 11 & 6,0 \\
Gorro & 26 & 14,2 & 107 & 58,7 & 21 & 11,5 & 12 & 6,5 & 16 & 8,7 \\
\hline
\end{tabular}

Dados diferentes foram encontrados por outros autores, que verificaram a utilização do jaleco pela equipe de enfermagem em apenas $33 \%$ dos procedimentos, sendo estes apenas quando em contato com sangue e secreções ${ }^{(13)}$. O jaleco reduz a possibilidade de transmissão de microrganismos para o profissional, equipe e pacientes, sendo assim, imprescindível a utilização deste ao atender os pacientes ${ }^{(4)}$.

Em relação às luvas $96(52,7 \%)$ e 85 $(46,7 \%)$ fazem uso sempre e em situações específicas respectivamente, demonstrando a sua utilização durante as atividades práticas.

Outro dado relevante é o fato de 110 $(60,4 \%)$ alunos afirmarem que utilizam óculos protetores em situações específicas. Os óculos protetores devem ser usados sempre que houver a possibilidade de respingos de material biológico durante a realização de um procedimento $^{(3)}$.

Destacou-se que $14(7,6 \%)$ dos alunos nunca utilizaram óculos protetores, apesar de já estarem cursando o último ano do curso. Esses achados corroboram com outro estudo, no qual descreve que para alguns profissionais de enfermagem os óculos de proteção não foram reconhecidos como $\mathrm{EPI}^{(14)}$.

Observou-se em uma pesquisa que apenas um enfermeiro $(0,7 \%)$ não reconhece a necessidade da máscara e dos óculos protetores quando da possibilidade de respingos de sangue e fluidos corpóreos, mas os demais enfermeiros e todos os auxiliares de enfermagem indicaram a necessidade deles nessas situações ${ }^{(15)}$.

Em outro estudo o uso de luvas foi relatado por $97 \%$, enquanto o uso de aventais e de protetores oculares por $62 \%$ e $63 \%$ respectivamente ${ }^{(16)}$.

Ao serem indagados sobre o que é Equipamento de Proteção Individual 54 (29,6\%) referiram ser o equipamento utilizado para proteção contra contaminações de fluidos corporais, agentes patológicos e perfurocortantes. Já 41 alunos (22,5\%) escreveram quais são os equipamentos de proteção. Isso demonstra que eles possuem o conhecimento de quais são os equipamentos, mas não sabem definir qual a finalidade destes. Os demais conceituaram como equipamento utilizado para a proteção do profissional e contra acidentes de trabalho sem, contudo, especificar o tipo de acidente que se quer prevenir.

Em uma pesquisa sobre a compreensão do enfermeiro sobre as medidas de precauções padrão, os autores observaram que $75,6 \%$ dos enfermeiros compreendiam que as precauções padrão são utilizadas como estratégia de proteção nas atividades cotidianas da assistência à saúde, porém, 4,9\% às utilizam apenas para pacientes sabidamente infectados $^{(17)}$.

Ao serem questionados sobre a freqüência de troca de jaleco, verificou-se (Figura 1) que é feita diariamente por $129(70,9 \%)$ dos alunos; $12(6,6 \%)$ o trocam por período. Entretanto, 37 alunos afirmaram usar os seus jalecos por períodos maiores. Os jalecos devem ser trocados por período de atendimento ou, no máximo, diariamente, e sempre que estiverem visivelmente sujos ${ }^{(5)}$. 


\section{Frequência de troca de jaleco}

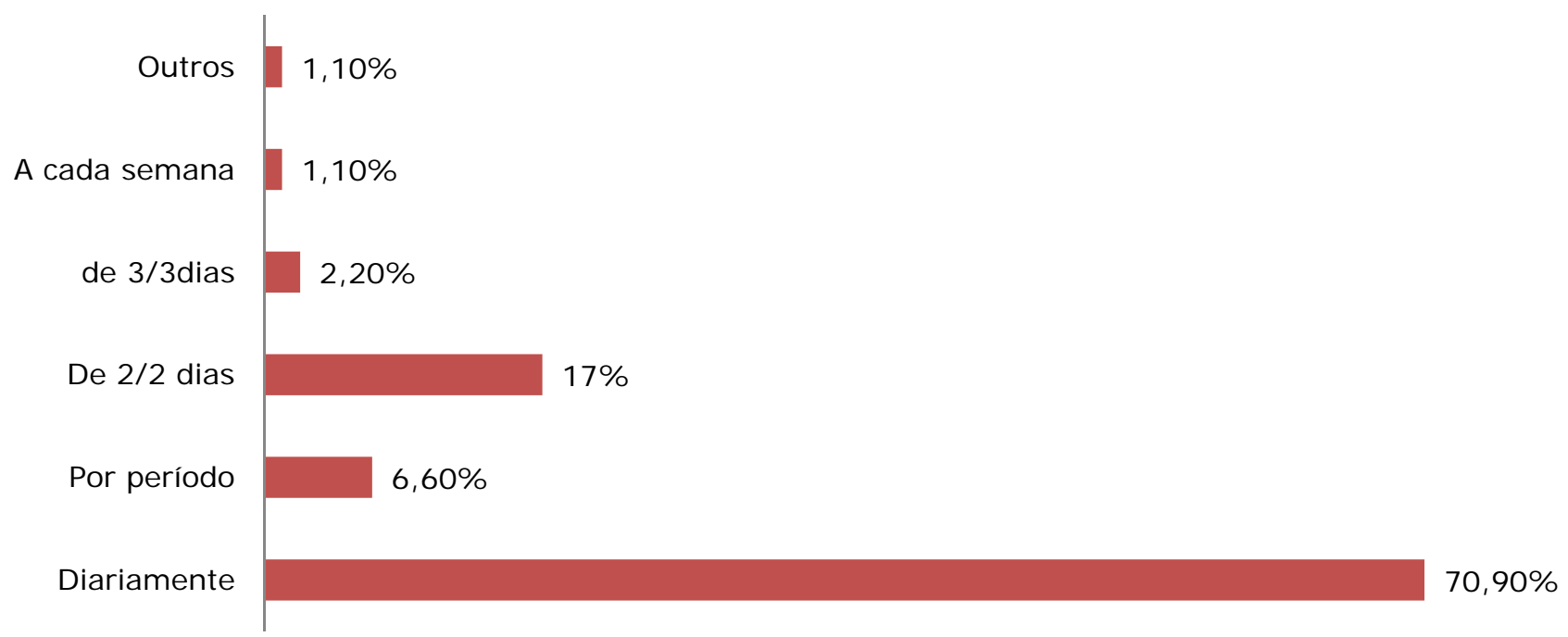

Figura 1: Distribuição dos acadêmicos de Enfermagem segundo a indicação para a troca de jalecos. Goiás, 2005.

Em um estudo cujo objetivo era descrever o uso e manuseio de EPI pelos alunos em uma instituição de ensino superior odontológico verificaram que a troca de jaleco é feita a cada período por $31,8 \%$ dos alunos, $38,3 \%$ o trocam diariamente, $10,2 \%$ a cada dois/ três dias e $2,5 \%$ pelo período de uma semana ${ }^{(5)}$. Isto vem confirmar os dados encontrados neste estudo, no qual a troca diária é realizada pela maioria dos alunos.

Outra indicação para a troca de jalecos foi referida por dois $(1,1 \%)$ dos alunos: dependendo da necessidade e se estiver visivelmente sujo.

Em relação às características do jaleco, 171 alunos $(94,0 \%)$ referiram que deve ter manga longa e $87(47,8 \%)$ que o jaleco deve ser longo (cobrir os joelhos). Entretanto, um $(0,5 \%)$ referiu que o jaleco deve estar acima do joelho e seis $(3,2 \%)$ acham que deve ser de manga curta.

Outras características foram referidas pelos alunos: apresentar o nome, estar limpo, ser fechado, ter punho com elástico, não ter gola, ter três bolsos e ser de um tecido que facilite a secagem para proporcionar a troca diária.

Os jalecos normalmente têm atendido mais aos aspectos estéticos do que funcionais. A qualidade do EPI deve ser mensurada pelo tipo de tecido, e o modelo deve promover a proteção dos braços e da roupa utilizada pelo profissional $^{(4)}$. As mangas longas são necessárias para a proteção dos braços, entretanto, dificultam a higienização das mãos. Talvez a solução seja o uso do punho que ajusta as mangas.

As luvas têm por finalidade proteger as mãos dos profissionais do contato com sangue e fluidos corpóreos, mucosas, pele com solução de continuidade, superfícies ou artigos potencialmente contaminados e reduzir a transmissão de microrganismos veiculados pelo profissional tanto para a equipe de trabalho, quanto para os pacientes ${ }^{(4)}$.

Verificou-se que $174(95,6 \%)$ dos alunos utilizam as luvas sempre que manuseiam sangue ou fluídos corpóreos, Tabela 2. 
Souza ACS, Neves HCC, Tipple AFV, Santos SLV, Silva CF, Barreto RAS. Conhecimento dos graduandos de enfermagem sobre equipamentos de proteção individual: a contribuição das instituições formadoras. Revista Eletrônica de Enfermagem [Internet]. 2008; 10(2):428-437. Available from: http://www.fen.ufg.br/revista/v10/n2/v10n2a14.htm

Tabela 2: Distribuição dos acadêmicos de Enfermagem segundo a prática do uso e manuseio das luvas de procedimento. Goiás, 2005. $(n=182)$.

\begin{tabular}{lcc}
\hline \multicolumn{1}{c}{ Prática quanto ao uso e manuseio de luvas de procedimentos } & F & \% \\
\hline Sempre que manusear sangue ou fluídos corpóreos & 174 & 95,6 \\
Substituída a cada paciente & 172 & 94,5 \\
Deve ser descartada logo após o seu uso & 171 & 94,0 \\
Não deve ser lavada, desinfetada ou esterilizada & 113 & 62,1 \\
Substituída no mesmo paciente sempre que mudar de sítio & 111 & 61,0 \\
\hline
\end{tabular}

Esses dados corroboram com um estudo no qual $131(97,8 \%)$ dos profissionais utilizam as luvas sempre que entram em contato com sangue e outros fluidos ${ }^{(15)}$

Analisando os fatores de influência na adesão às Precauções Universais em uma amostra de 806 enfermeiros, níveis elevados de adesão foram encontrados em relação ao uso de luvas e higienização das mãos. A maior adesão ao uso de luvas reflete a longa tradição com este tipo específico de equipamento de proteção( ${ }^{(18,19)}$.

Vale ressaltar o fato de 172 (94,5\%) alunos substituírem as luvas a cada paciente, indicando que além da proteção profissional, têm consciência do risco coletivo representado pelo uso inadequado das luvas.

Destaca-se que a maioria dos graduandos de enfermagem além de indicarem corretamente a indicação do uso das luvas, também as manuseiam conforme preconizado.

Imediatamente após o uso, as luvas devem ser retiradas, descartadas e em seguida proceder a higienização das mãos que em nenhuma hipótese deve ser negligenciada entre os contatos, e também não é admitido a lavagem das luvas. É indicada a troca das luvas entre procedimentos no mesmo paciente, após contato com material infectado para não disseminar infecção para outros sítios do corpo $^{(3)}$. Essa prática foi demonstrada por 111 (do total de 182) estudantes, revelando um ponto crítico no uso e manuseio de luvas que merece atenção especial no processo ensinoaprendizagem.

Em relação à prática de uso dos óculos de proteção, identificou-se que $173(95,1 \%)$ dos alunos referiram o utilizar sempre que há possibilidade de respingo e/ou aerossóis de sangue ou fluídos corpóreos, e 11 (6,0\%), relataram que não há esta indicação na prática do enfermeiro. Esses dados diferem de outros estudos, que mostraram baixa adesão dos profissionais ao uso de óculos protetores, sendo este o EPI menos utilizado ${ }^{(2,14)}$.

Um dado relevante foi o fato de sete $(3,8 \%)$ alunos afirmarem não utilizar os óculos protetores, pois fazem uso de óculos corretivos. Os dados encontrados possuem coerência com outro estudo no quais 11 não utilizam os óculos protetores por usarem óculos corretivos $^{(15)}$. Óculos corretivos não substituem os óculos protetores, há modelos que são perfeitamente adaptáveis aos óculos de correção.

Os óculos protetores são artigos reutilizáveis e requerem processos de descontaminação entre os atendimentos. Verificamos que $121(66,5 \%)$ promovem a lavagem com água e sabão após o uso e 118 $(64,8 \%)$ alunos realizam a desinfecção diária com álcool a $70 \%$. Os óculos são considerados artigos não críticos, cuja reutilização pode ser feita apenas com a limpeza. Contudo quando há exposição a secreções, como ocorre com os aerossóis, a desinfecção é aconselhada ${ }^{(3)}$.

O processamento dos óculos protetores é uma temática ainda não compreendida pelos profissionais. Esses dados e o do estudo realizado com alunos do curso de odontologia mostraram que há falhas na construção desse conhecimento durante o período de formação acadêmica. Essas autoras encontraram que 73 $(46,5 \%)$ alunos realizam limpeza e desinfecção, $52(33,1 \%)$ apenas limpeza e 29 (18,5\%) apenas desinfecção nos óculos de proteção(5).

Quanto à prática de uso da máscara (Tabela 3), verifica-se que 171 (94,0\%) dos graduandos fazem uso sempre que há possibilidade de respingos e/ou aerossóis de sangue e fluídos corpóreos. Observou-se também que mais da metade dos alunos 112 $(61,5 \%)$ a descarta após cada paciente, ou pelo menos quando estão úmidas como citado por $110(60,4 \%)$ dos alunos. As máscaras 
Souza ACS, Neves HCC, Tipple AFV, Santos SLV, Silva CF, Barreto RAS. Conhecimento dos graduandos de enfermagem sobre equipamentos de proteção individual: a contribuição das instituições formadoras. Revista Eletrônica de Enfermagem [Internet]. 2008; 10(2):428-437. Available from: http://www.fen.ufg. br/revista/v10/n2/v10n2a14.htm

cirúrgicas devem ser utilizadas de forma a sempre que possível e descartada cobrir boca e nariz, trocadas entre clientes imediatamente após o uso ${ }^{(3)}$.

Tabela 3: Distribuição dos acadêmicos em Enfermagem segundo a prática de uso e manuseio da máscara. Goiás, 2005 ( $n=182$ ).

\begin{tabular}{lcc}
\hline \multicolumn{1}{c}{ Prática quanto ao uso e manuseio da máscara } & F & $\%$ \\
\hline Sempre que houver possibilidade de respingos e/ ou aerossóis & 171 & 94,0 \\
Descartar após cada paciente & 112 & 61,5 \\
Descartar sempre que estiver úmida & 110 & 60,4 \\
Descartar ao final do turno de trabalho & 54 & 29,7 \\
Não há esta indicação na minha prática & 3 & 1,6 \\
\hline
\end{tabular}

Apesar da eficácia das Precauções Padrão, nem sempre elas são observadas, principalmente, quanto ao uso do EPI, que até se tornarem integrantes da rotina dos profissionais, mostraram-se como incômodos e difícil de serem aceitos ${ }^{(15)}$. Quanto as dificuldades encontradas pelos alunos para a utilização de Equipamento de Proteção Individual (Tabela 4), observou-se que 110 $(57 \%)$ relataram barreiras relacionadas à inexistência, qualidade e tamanho inadequado dos EPI.

Tabela 4: Dificuldades indicadas pelos acadêmicos de Enfermagem para o uso dos Equipamentos de Proteção Individual. Goiás, 2005 ( $n=182)$.

\begin{tabular}{lcc}
\hline \multicolumn{1}{c}{ Fatores dificultadores } & F & $\%$ \\
\hline Barreiras relacionadas à inexistência ou qualidade dos EPI & 110 & 57 \\
Incômodo e interferência do EPI na realização do atendimento & 94 & 51,1 \\
Nenhum & 26 & 14,2 \\
Falta de conhecimento e conscientização da equipe sobre EPI & 25 & 13,5 \\
Outros & 15 & 8,24 \\
Falta de tempo e situações de emergência & 14 & 7,6 \\
Falta de incentivo ao uso & 7 & 3,7 \\
\hline
\end{tabular}

Pesquisas encontraram como agravantes para a não utilização do EPI a sobrecarga de trabalho, situações de emergência, má qualidade dos materiais, tamanho inadequado, pressa e a não disponibilização de EPI pelo serviço $^{(1,15)}$. Esses achados vêm de encontro aos dados da pesquisa em questão.

O tamanho inadequado do Equipamento de Proteção Individual especialmente, das luvas de procedimento, quando a numeração é maior do que a apropriada ao usuário, dificulta o desempenho técnico, podendo interferir na qualidade do procedimento ou mesmo favorecer riscos de acidentes com perfurocortantes.

A falta de material é apontada pelos sujeitos como uma grande barreira para a efetivação das Precauções Padrão no cotidiano. A assistência à saúde pressupõe toda uma estrutura de suporte de materiais permanentes, de consumo, e equipamentos. Não havendo esta contrapartida é impossível o profissional adotar as práticas das $\mathrm{PP}^{(4)}$. Vale lembrar que a NR 32/2005 estabelece como dever da empresa fornecer o EPI em quantidade e qualidade e como direito do trabalhador o seu acesso facilitado ${ }^{(12)}$.

Destaca-se que $94(51,1 \%)$ citaram o incômodo, especialmente o calor, apresentando assim interferência do EPI como barreira para a sua utilização. Dentre as outras dificuldades apresentadas os graduandos citaram ainda a sobrecarga de trabalho, aparência, preconceito dos colegas e do próprio paciente, dificuldade em trocar o EPI com freqüência, falta de hábito, falta de vontade, fadiga e o fato de já usar óculos de correção.

Em um estudo com a Equipe de Resgate do Corpo de Bombeiros de Goiás, foram encontrados como dificultadores da utilização do EPI sobrecarga de trabalho $(72,7 \%)$, falta de material $(36,3 \%)$, falta de incentivo $(29,5 \%)$, situações de emergência $(29,5 \%)$ e falta de tempo $(20,4 \%)^{(7)}$.

$\mathrm{Na}$ área de saúde os aparatos de proteção individual e coletiva, inicialmente exigem perseverança para sua adaptação, pois até que 
passem a pertencer à rotina diária com naturalidade, parecem ser incômodos, restringem os movimentos, dificultam a percepção tátil, alteram a temperatura corporal, ou mesmo atrasam a execução de serviço pela simples alteração da rotina(20).

\section{CONCLUSÃO}

Este estudo que verificou a compreensão dos alunos de graduação em enfermagem acerca do uso de Equipamento de Proteção Individual e ainda buscou identificar a contribuição dos cursos de graduação em enfermagem para a construção do conhecimento dos graduandos sobre o uso do EPI permitiu concluir que:

- todos os graduandos afirmam fazer uso de EPI durante a sua prática assistencial e a maioria refere ter estudado sobre esse tema em disciplina curricular.

- a maioria dos alunos conhece as indicações de uso do EPI e os mais utilizados são jaleco e luvas.

- apesar da compreensão sobre a indicação de uso do EPI ainda apresentam dificuldades quanto ao uso e manuseio, especialmente em relação às máscaras e óculos protetores, caracterizado pela multiplicidade de condutas na freqüência de trocas e no reprocessamento.

- os acadêmicos encontram, na prática, dificuldades/barreiras para utilização de EPI, sendo as principais relacionadas à inexistência dos equipamentos, à sua qualidade e ao próprio incômodo gerado pelo seu uso.

- os cursos de graduação em Enfermagem no Estado de Goiás têm contribuído para o conhecimento dos graduandos sobre 0 uso de EPI. Entretanto, a construção deste conhecimento ainda não tem sido suficiente para instrumentalizar estes alunos para o enfrentamento das barreiras encontradas no cotidiano dos serviços de assistência à saúde quanto à disponibilização, qualidade e manuseio do EPI.

A formação e preparo dos enfermeiros é uma questão fundamental, para o exercício consciente e seguro da profissão. O graduando deve ser capaz de no seu cotidiano de trabalho não apenas usar e manusear adequadamente o EPI, mas principalmente de transformar a realidade da prática do uso de EPI.

Neste contexto, entende-se que a educação conscientizadora assume relevância em qualquer programa de biossegurança, por meio de estratégias participativas e motivacionais, capaz de criar nos profissionais não só a responsabilidade social, mas, principalmente a consciência de que podem atuar de forma a preservar o meio ambiente, a melhorar a qualidade de vida e a proteger a própria vida.

\section{REFERÊNCI AS}

1. Marziale MHP, Rodrigues CM. A produção científica sobre os acidentes de trabalho com material perfurocortante entre trabalhadores de Enfermagem. Rev Latino- Am. Enfermagem. 2002; 10(4):571-77

2. Brevidelli MM, Cianciarulo TI. Níveis de adesão às precauções-padrão entre os profissionais médicos e de enfermagem de um hospital universitário. Online Braz J Nurs [Internet]. 2006 [cited 2006 jul 20];5(1). Available from: http://www.uff.br/objnursing/index.php/nursing Larticle/view/291/57

3. Garner JS. Hospital Infection Control Practices Advisory Committee. Guideline for isolation precautions in hospitals. Infect Control Hosp Epidemiol. 1996; 14(5): 53-80.

4. Melo DS. Adesão dos enfermeiros às precauções padrão à luz do modelo de crenças em saúde [dissertação]. [Goiânia]: Faculdade de Enfermagem/UFG; 2005. 191 p.

5. Tipple AFV, Souza ACS, Souza CPS, Paiva EMM, Pereira MS. Equipamentos de Proteção Individual: uso e manuseio por alunos em uma instituição de ensino odontológico. Rev $A B O$ Nac. 2003; 11(3): 153-61.

6. Keller S, Daley K, Hyde J, Greif RS, Church DR. Hepatitis $C$ prevention with nurses. Nursing and Health Sciences. 2005; 7(2): 99-106. 
7. Florêncio VB, Rodrigues CA, Pereira MS, Souza ACS. Adesão às precauções padrão entre os profissionais da equipe de resgate do corpo de Bombeiros de Goiás. Rev Eletrônica de Enfermagem [Internet]. 2003 [cited 2005 mar 19];5(1):43-8. Available from: http://www.fen.ufg.br/revista/revista5_1/pdf/a desao.pdf.

8. Ceccim RB, Feverwerker LCM. Mudança na graduação das profissões de saúde sob o eixo da integralidade. Cad. Saúde Pública. 2004; 20(5): 1400-10.

9. Ministério da Educação; Conselho Nacional de Educação, Câmara de Educação Superior. Resolução CNE/CES 3/2001 - Institui Diretrizes Curriculares Nacionais do Curso de Graduação em Enfermagem. Brasília: Ministério da Educação, 2001.

10. Tipple AFV, Pereira MS, Hayashida M, Moriya TM, Souza ACS. O ensino do controle de infecção: um ensaio teórico-prático. Rev LatinoAm. Enfermagem. 2003; 11(2): 245-50.

11. Sarquis LMM, Felli VEA. O uso dos equipamentos de proteção individual entre os trabalhadores de enfermagem acidentados com instrumentos perfurocortantes. Rev Brasileira de Enfermagem. 2000; 53(4):564-73.

12. Ministério do Trabalho e Emprego. Portaria $\mathrm{n}$-485, de 11 de novembro de 2005. Aprova a Norma Regulamentadora no 32. Segurança e Saúde no Trabalho em Estabelecimentos de Saúde. Brasília: Ministério do Trabalho e Emprego; 2005.

13. Lopes $\mathrm{MH}$, Moromizato SS, Veiga JFF. Adesão às medidas de precaução padrão: relato de experiência. Rev Latino- Am. Enfermagem. 1999; 7(4):83- 8.

14. Ennes LD. O uso, desuso ou uso inadequado dos equipamentos de proteção individual pela equipe de enfermagem na prevenção dos riscos com material biológico [dissertação]. [Rio de Janeiro]: Escola de Enfermagem Anna Nery/UFRJ ; 2002. $142 \mathrm{p}$

15. Souza ACS. Risco biológico e biossegurança no cotidiano de enfermeiros e auxiliares de enfermagem [tese]. [Ribeirão Preto]: Escola de Enfermagem de Ribeirão Preto/USP; 2001.

16. Gershon RRM, Vlahov D, Felknor SA, Vesley D, Johnson PC, Delclos GL, et al. Compliance with universal precautions among health care workers at three regional hospital. Am J Infect Control. 1995; 23(4): 225-36.

17. Melo DS, Souza ACS, Tipple AFV, Neves ZCP, Pereira MS. Compreensão sobre precauções padrão pelos enfermeiros de um hospital público de Goiânia- GO. Rev LatinoAm. Enfermagem. 2006; 14(5):720-27.

18. Dejoy DM, Searcy CA, Murphy LR, Gershon RRM. Behavioral-diagnostic analysis of compliance with universal precautions among nurses. J Occup Health Psychol. 2000;5(1): 12741.

19. Michalsen A, Delclos GL, Felknor AS, Johnson PC, Vesley D, Davidson AL, et al. Compliance universal precautions among physicians. J Occup. Enriron. Méd. 1997; 39(2): 130-7.

20. Souza ACS, Tipple AFV, Pereira MS, Prado MA. Desafios para o controle de infecção nas instituições de saúde: percepção dos enfermeiros. Rev Cienc. Enferm. 2002;8(1): 1930.

Artigo recebido em 22.03.07

Aprovado para publicação em 30.06.08 